\title{
SOLAR SALTWORKS' WETLAND FUNCTION
}

\author{
N.A. KOROVESSIS ${ }^{1, *}$ \\ T.D. LEKKAS ${ }^{2}$
}

\author{
${ }^{1}$ Hellenic Saltworks S.A. \\ Asklipiou 1 str., 10679 Athens, Greece \\ ${ }^{2}$ University of the Aegean, Dept. of Environmental Studies \\ University Hill, 81100 Mytilene, Greece
}

Received: $26 / 08 / 08$

Accepted: 20/10/08 *to whom all correspondence should be addressed: e-mail:nkor@hol.gr

\begin{abstract}
Salt, the world's best-known mineral, is the chemical substance most related to human civilization history. Apart from his significance for the creation of life on the planet it has been used as main commodity for centuries.

Man produces salt by solar evaporation since the dawn of human civilization. Nevertheless, recognition of the unique coastal ecosystems that developed in parallel with the Solar Saltworks production process evolution is often lacking. The environmental uniqueness of Solar Saltworks, particularly current operations, is based on the fact that they are integrated, constructed coastal ecosystems, where regular and hyper saline environments coexist and establish high significant shelters for wildlife.

The basic steps of the Solar Salt Production Process Evolution are identified. The biological process that develops along with the salinity vector in the evaporating ponds and crystallizers produces food for many kinds of birds. Hundreds of bird species depend on Solar Saltworks ecosystem to feed and/or nest. Many of them have been identified as endangered species or protected by European or International conventions.

The operation of the Coastal Saline Wetlands is outlined and compared with Solar Saltworks ecosystem. We emphasize on the case of "Aliki" lake, which is a natural saline coastal wetland located in Lemnos, a Northern Aegean Sea Island in Greece.
\end{abstract}

KEYWORDS: Solar Saltworks, Production process, Biological process, Salinas, Wetlands, Lemnos, Aliki Lake.

\section{INTRODUCTION}

Salt, the common name for the compound of sodium $\left(\mathrm{Na}^{+}\right)$and chloride $\left(\mathrm{Cl}^{-}\right)$, is the first substance after water to have attracted humans' attention in their evolution from wilderness to civilisation.

It is common knowledge that life began in the oceans, where the first monocellular organisms were created. Although some creatures left their marine environment after a long evolutionary process, they continued being dependent on salt. Nowadays, we know that sodium chloride is the basic extra-cellular electrolyte of the human body and that the salinity levels of the environment where human foetuses develop are similar to those of the sea! Therefore, salt has remained a necessary element for the survival and proliferation of not only herbivorous animals, which take the necessary quantity of salt by licking the salty soil, but also for carnivorous ones, which ensure the necessary intake of salt from the blood of their prey (Young, 1977).

The time when humans began engaging in farming activities and became settlers coincides with their search for salt, which is provided by nature in abundance. Salt along with water, cereals (bread) and the meat of domestic animals constituted the staple basis of human society in its infancy (Baas-Becking, 1931). 
Initially, salt was used to cater for the needs of human diet and later its significant food preserving property was discovered. This particular property made salt one of the most important commodities for centuries, comparable to the importance of oil in our times.

The root of both words is the Latin sal (salt), which derives from the Greek words ă $\lambda \varsigma$ (sea) and ă $\lambda \boldsymbol{\alpha} \varsigma$ (salt). The initial letter $\boldsymbol{s}$ in the Latin word derives from the early Greek whereby the words for salt and sea started with an $\boldsymbol{s}$ too. Later, in ancient Greek, this $\boldsymbol{s}$ was dropped and was replaced by the breathing (Korovessis and Lekkas, 2000).

Although the industrial revolution resulted in a gradual decline of the use of salt as food preservative, people's needs did not follow the same trend. The extensive use of sodium chloride as raw material in the chemical industry have increased salt consumption worldwide, with annual figures reaching 200 million tonnes nowadays. One third of this is produced in Solar Saltworks. About $20 \%$ of the international salt production is destined for human consumption, whereas $55 \%$ is used in the chemical industry and $15 \%$ for de-icing roads in winter.

\section{SOLAR SALTWORKS PRODUCTION PROCESS}

\section{a. Salt recovery from seawater}

Solar Salt $(\mathrm{NaCl})$ is recovered from seawater, a practically inexhaustible raw material, by solar evaporation.

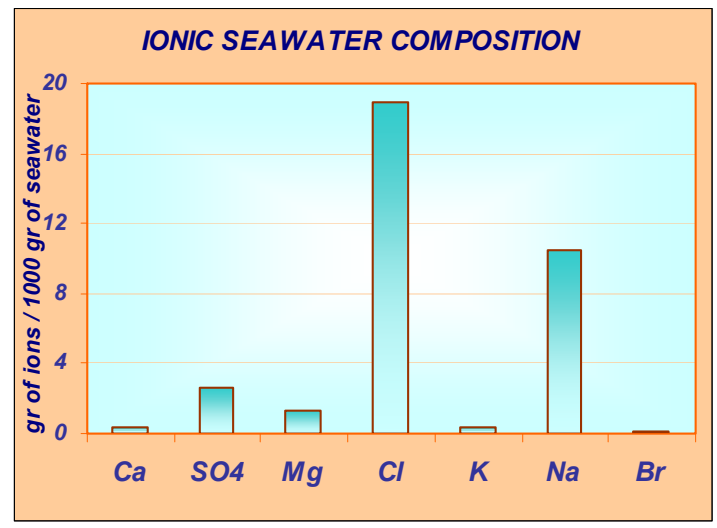

(a)

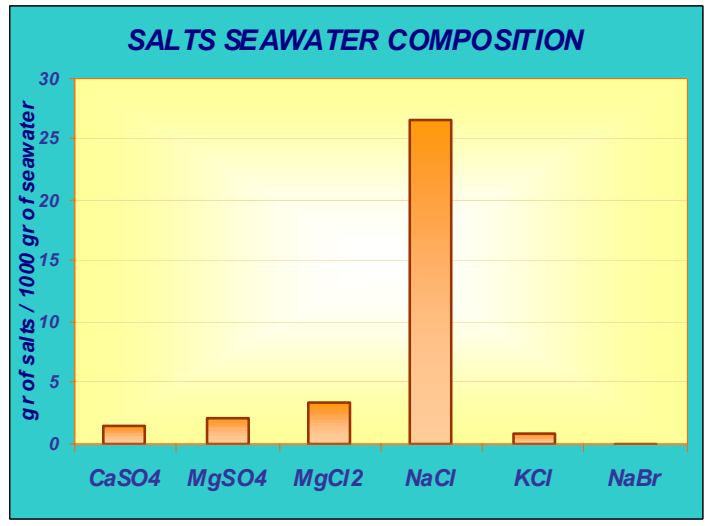

(b)

Figure 1. Ionic (a) and salts (b) sea water composition (Bassegio, 1974)

Production of salt from seawater involves the selective recovery of pure $\mathrm{NaCl}$, free of other soluble or non-soluble salts or other substances. Condensation of an appropriate quantity of seawater leads to the fractional crystallisation of all salts contained; a process based on their varying solubility. Thus solar evaporation of seawater results in the successive crystallisation initially of the less soluble salts $\left(\mathrm{CaCO}_{3}, \mathrm{CaSO}_{4}\right)$, followed by $\mathrm{NaCl}$ and finally Magnesium salts.

Solar Salt workers use the empirical Baume $\left({ }^{\circ} \mathrm{Be}\right)$ scale, to measure the concentration of brines. According to that scale the seawater concentration is approx. $3.5{ }^{\circ} \mathrm{Be}$. The crystallization of $\mathrm{CaCO}_{3}$ begins at $4.6^{\circ} \mathrm{Be}$ and that of $\mathrm{CaSO}_{4}$ at $13.2^{\circ} \mathrm{Be}$. $\mathrm{NaCl}$ crystallizes at $25.7^{\circ} \mathrm{Be}$, followed by the more soluble $\mathrm{Mg}$ salts at $30^{\circ} \mathrm{Be}$.

\section{b. Solar Saltworks production process evolution}

\section{Stage I}

Originally humans must have found salt in coastal concavities, lagoons or lakes where seawater is trapped, evaporated in the sun and deposited its salt content. It can be reasonably deduced that, after a long period of observation and knowledge-building, humans eventually copied nature and began producing salt in quantities meeting their personal and social needs, moving away from nature's production rates. That is considered the first step 
and is indentified as the first stage (STAGE I) in solar salt production process hereby described (Figure 2).

Although with this method one can produce high quality salt on the surface of the brine, it has certain disadvantages since the salt that precipitates contains all the ingredients of seawater and it is very difficult to produce relatively pure $\mathrm{NaCl}$, in fact, it requires great experience. Above all, its main disadvantage consists in the fact that it is actually a batch process with limited production rates.

\section{Stage II}

Man's need in improving Solar Salt quality and increasing production rates led him to the second step in its production process. That step must have been made by the division of the single evaporation pond into two (Figure 2, STAGE II). The first pond, usually called nurse pond, was used for the production of saturated (with respect to $\mathrm{NaCl}$ ) brine, which was fed into the second pond, usually called crystallizer.

Thus, it was made possible to:

- Achieve continuous production (crystallization) of salt and therefore to unbound the salt production rate.

- Eliminate those seawater salts, with less solubility than $\mathrm{NaCl}$ (i.e. $\mathrm{CaCO}_{3}$ and $\mathrm{CaSO}_{4}$ ), since these are now crystallize in the first basin and remain there.

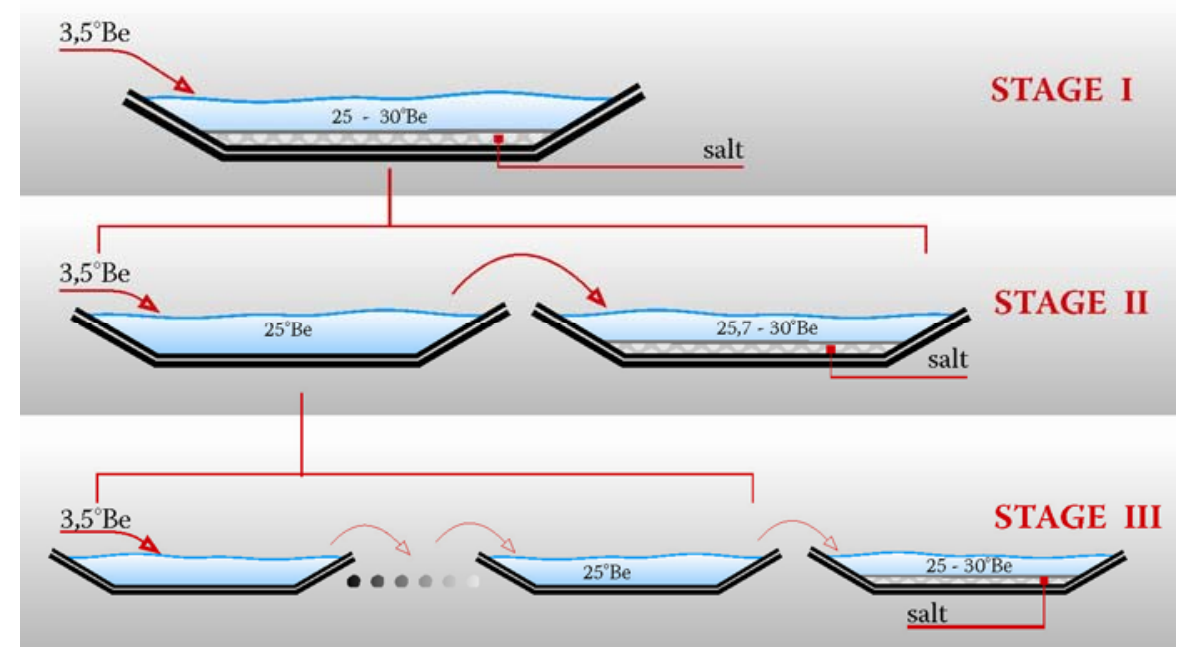

Figure 2. Main steps in Solar Saltworks production process evolution.

\section{Stage III}

The third step concerned the division of the nurse pond into several interconnected ponds. That step was made to improve even more salt quality and production rates and actually lead us to the operating design scheme of current Solar Saltworks. With this design, seawater enters the first pond and, as it flows through the next ponds and evaporates in the sun, its concentration increases. Thus, by the time it reaches the last pond, which has now become the nursing pond, it has a concentration of $25.7^{\circ} \mathrm{Be}$, corresponding to the saturated brine in terms of $\mathrm{NaCl}$.

With this production process one is able to achieve optimum Solar Salt quality and production rates because we can:

- Control better both the brine's concentration and quantity which is fed through the pond system, thus resulting in optimized and steady conditions in every pond and especially in the crystallizers where salt crystallizes and

- Increase further the salt production rate because the average brine concentration in the pond system decreases drastically compared with STAGE II - it is known that the evaporation rate increases as brine concentration decreases. 


\section{Important remarks:}

In the multiple pond case (STAGE III) the salinity gradient changes with respect to area (from the first pond to crystallizers) whereas in the single pond case (STAGE I) it changes with respect to time. That means that whatever takes place in STAGE I through a certain period of time in terms of physicochemical and biological processes, in STAGE III it occurs at any moment of that period. In other words every pond of STAGE III is a live phase (a picture) of STAGE I and most important they are steady in time, because every pond in modern Solar Saltworks has more or less fixed salinity. Obviously the multiple ponds system is more manageable, stable and integrated ecosystem than the single pond.

These three stages constitute man's basic steps towards improving Solar Salt Producing Technology. Unfortunately, there are no data or information available confirming the time when the aforementioned production methods were first used, although it is certain that it has not been a uniform process throughout the world. The fact that all stages described above are still alive even nowadays is impressive. In Greece, for instance, the Saltworks on the island of Kythera still produce salt in concave rocks by the sea.

\section{c. Current Solar Saltworks production process}

Modern Solar Saltworks consist of a system of shallow ponds (15-60 cm deep), connected mainly in series. Their bottom is natural and has the appropriate clay composition to ensure very low water permeability. Their operation principle is basically the one described in STAGE III. The only differences that have occurred, since the method was first applied, concern its optimisation as well as the means by which brine is transferred and salt is harvested, resulting from subsequent technological progress.

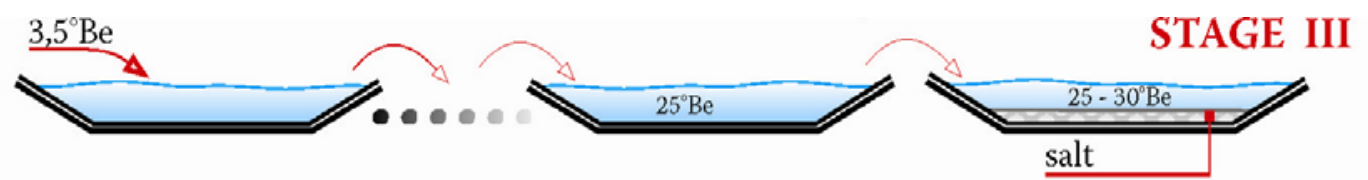

Figure 3. Current Solar Saltworks production process scheme

According to this process, the ponds are divided into two basic groups. The first group, usually called evaporating ponds, is where seawater is concentrated up to saturation point in terms of $\mathrm{NaCl}\left(25.7^{\circ} \mathrm{Be}\right)$. Their bottom is totally natural without any intervention and the concentration of contained brine covers the whole range from $3.8^{\circ} \mathrm{Be}$ (almost seawater) to $25.7^{\circ} \mathrm{Be}$, corresponding to the last pond which feeds the crystallizers continuously with the required saturated brine (nurse pond). They cover almost $90 \%$ of the Saltworks production area since the seawater to be concentrated up to the point of salt crystallization, $90 \%$ of its water content has to evaporate.

The second group, called crystallizers or pans, consists of the ponds where salt crystallizes via further evaporation of the brine up to $28-29^{\circ} \mathrm{Be}$. Crystallizers take up the remaining $10 \%$ of the production area. These ponds are specially designed and have their bottom levelled and concentrated, aiming to facilitate and optimise mechanical salt harvesting.

A salinity (concentration) vector is created throughout the ponds of the Saltworks with a simultaneous and continuous reduction of the volume of seawater, which initially entered the pond system. This is the physicochemical process of salt production. This is actually the process that current Solar Saltworks use to recover salt from seawater, although there have been improvements and variations, allowing for the production of some hundred to some million tonnes of salt, depending on the size of the area in use.

Surprisingly enough, despite rising salinity, life in the ponds does not stop. Seawater organisms gradually disappear as they move from the initial pond to the hostile environment of the others. However, other organisms develop in their place and, as there is no competition, they proliferate. Such large populations are able to survive in areas with different concentration levels (that is, in different ponds) because of their varying sensitivity to the ion 
composition of the medium they inhabit (Davis, 1974). Thus, in parallel with the physicochemical process, a chain of organisms is developed in the evaporating ponds system, similar to those of naturally saline or hyper saline coastal ecosystems, constituting the biological process of Solar Salt production process. That process depends on the quality of feeding seawater, the prevailing conditions in the ponds, such as, brine temperature, depth, turbidity and concentration, the control of the physicochemical process during salt production and the overall design of the Saltworks (Davis, 1980; McArthur, 1980).

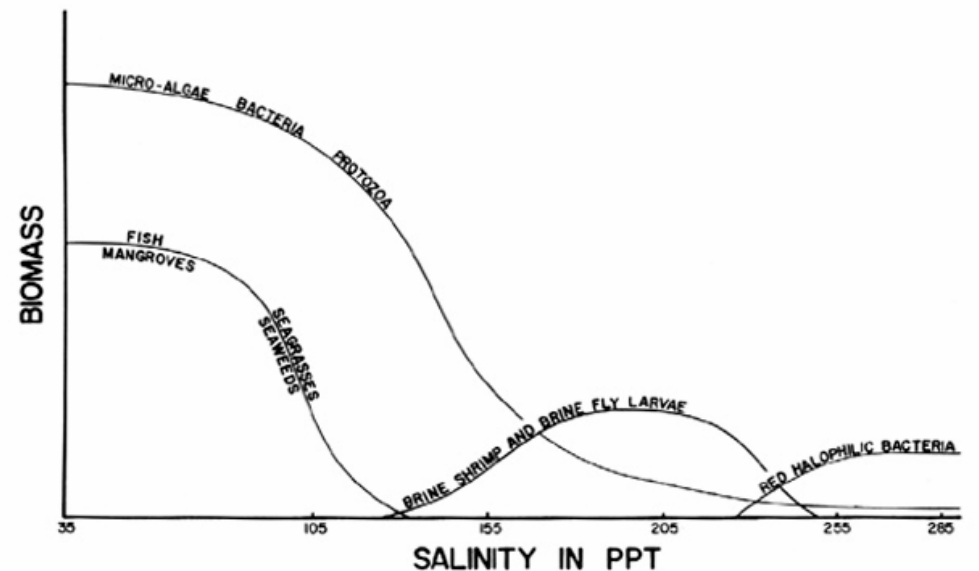

Figure 4. Rough estimate of principal organisms in Solar Saltworks (Davis, 1993)

The biological process interacts with the physicochemical process and it is in admirable harmony with the production process (Davis, 1980):

- It produces the appropriate quantity of organic matter, which is a source of energy for the various organisms, and reduces the permeability of the bottom of the ponds, thus minimising brine losses, particularly at low concentrations,

- It colours red the concentrated brines in the crystallizers thus, eliminating solar radiation reflection from the white salt bed.

- $\quad$ Finally it creates and maintains the appropriate conditions especially in the crystallizers for high quality salt production.

The optimal operation of Solar Saltworks is impossible without maintaining at their ponds system a healthy and stable ecosystem (Davis, 1993). Comparing modern with traditional Solar Saltworks, whose operation is fragmentary with negligent brine flow control, we end up with the surprising paradox that modern Solar Saltworks are better and more stable ecosystems than the traditional ones!!

\section{d. Wetland function}

It is already shown that as the production process moves from STAGE I to STAGE III the wetland function of Solar Saltworks emerges and becomes more and more stable (Figure 5). Current Solar Saltworks use an evaporating pond system with increasing brine concentration, from 3.5 to $26{ }^{\circ} \mathrm{Be}$, to feed the crystallizers. That system, actually transforms the Solar Saltworks into integrated coastal ecosystems, because it almost covers $90 \%$ of the total production area.

Solar Saltworks are specially designed according to their area characteristics and the prevailing whether conditions. They are actually constructed coastal ecosystems, unique in terms of their architecture. They combine their production process with the conservation of the environment, which is highly valued in our times.

The ecological importance of the Saltworks is mainly connected to their ornithological interest. Basic organisms of the biological system described above constitute excellent food for a large number of birds living in the Saltworks for this matter. Certain species of birds, especially Avocet, Black-necked Grebe, Kentish Plover etc., depend directly on Saltworks 
productivity since their diet is exclusively based on Artemia salina. Artemia is also part of the diet of the beautiful flamingos and it colours orange their feathers.

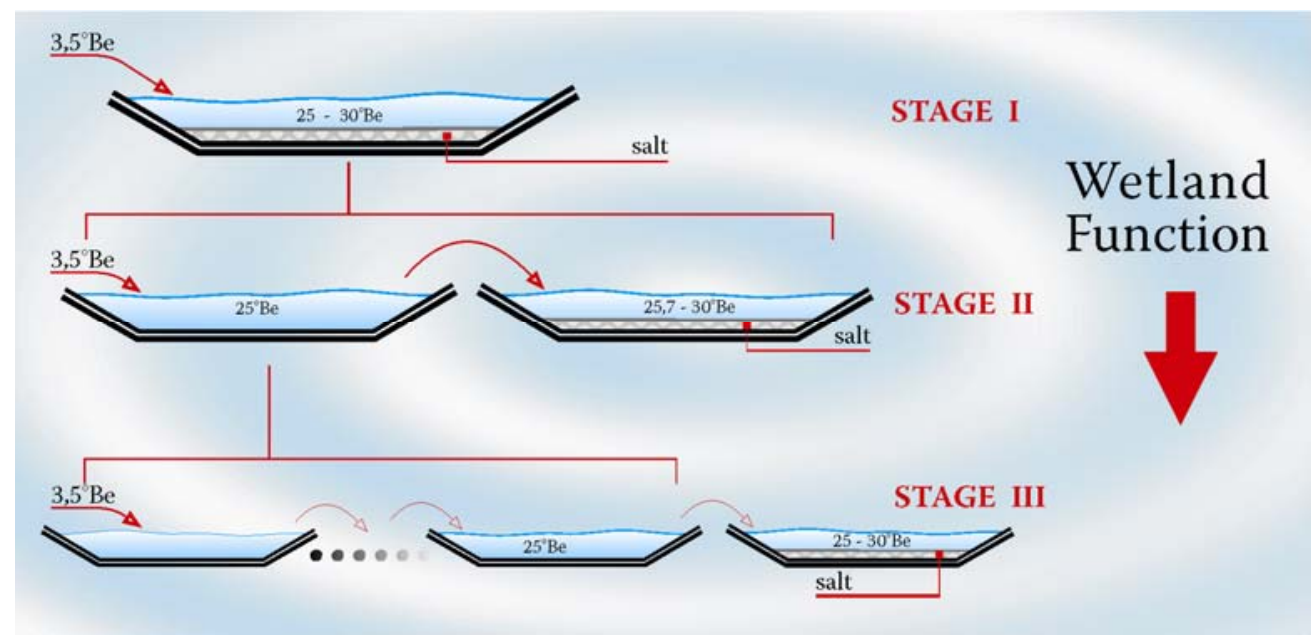

Figure 5. Solar Saltworks wetland function

More than 100 species of birds have been observed in every Solar Saltworks in Greece (188 in Kitros Saltworks in 1990). Many of them are protected by Greek, European or International conventions.

\section{COASTAL WETLANDS vS. SOLAR SALTWORKS}

Solar Saltworks pond system is continuously fed with seawater during the production period. The seawater inflow rate is controlled either by wooden gates, if we take advantage of the sea tidal waves, or by using axial flow pumps. Natural coastal wetlands are fed with seawater only by the action of sea tidal waves and their salinity increases due to the prevailing higher evaporation rates than the open sea. In the cases of wetlands where the brine concentration reaches crystallization point, salt crystallizes and finally the lake may undergoes a dry period without any wetland function. We can distinguish two general cases of natural coastal wetlands with shallow waters (Figure 6):

Case a. Those where the seawater under some special hydro-geological conditions is trapped and salt is produced and

Case $b$. Those where the sea water enters and renew more or less freely and the brine's concentration never reaches crystallization point.

If we compare figure 6 with the three stages we have indentify in Solar Salt Production Process Evolution (Figure 2) we can conclude that the wetlands operating scheme can be categorized to the single pond case (Figure 2, STAGE I). We can easily observe that the salinity gradient in the natural coastal wetlands changes with respect to time whereas in Solar Saltworks, the multiple pond case (Figure 2, STAGE III) with respect to their area.

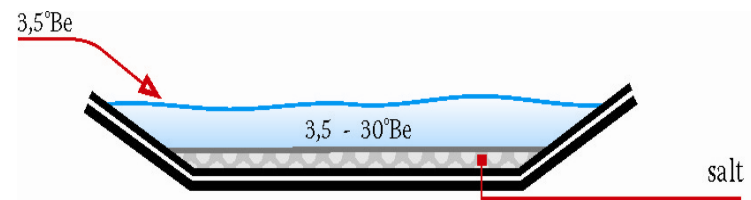

Case a. Traped seawater

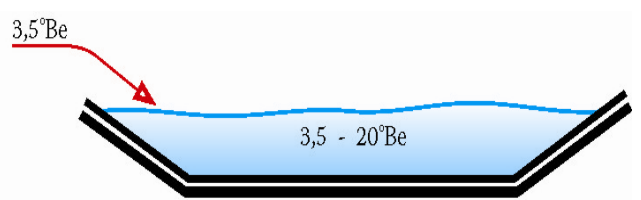

Case b. Freely entering seawater

Figure 6. Coastal Wetlands operating scheme

Following our remarks on Solar Saltworks production process evolution we can say that all phases of coastal wetlands through a whole year are present at any moment in Solar Saltworks and spread to their production area. In other words every pond of Solar Saltworks 
is a picture of coastal wetlands in terms of physicochemical and biological processes. Solar Saltworks ponds conditions do not change in time and their salinity starts from that of seawater up to over saturated brines. Obviously Solar Saltworks constitute more manageable, stable and integrated ecosystems than Coastal Wetlands! Additionally they operate through the whole year without any dry period. Even in the case of seasonal Saltworks the evaporating ponds never dry out, if during the seized period care is being taken from salt workers to feed every pond with the proper amount of brine in order to retain the ecosystem in function. The difference with the operating period however relies in the fact that there is no brine circulation and that the brine salinity never reaches saturation.

Important differences that are also in favour of Solar Saltworks are derived from fact that they are consisting from more than one ponds are also the following:

- In solar Saltworks dikes, birds can find more area for nesting

- Small birds find more area with shallow waters where they can feed, comparing with the case of one big lake

- Salt is produced only in the $10 \%$ of the total production area whereas in natural saline wetlands where is produced it covers the whole area.

It is also worth mentioning that Solar Saltworks are free of any chemical substances (fertilisers, etc), which the inflow rainwater conveys into the Coastal Wetlands from the surrounding area.

\section{LEMNOS Solar Saltworks PROJECT}

"Aliki" is a natural coastal lake with $6,300,000 \mathrm{~m}^{2}$ area, located in the Island of Lemnos in Northern Aegean Sea, Greece. Its operation scheme is similar to those of fig. 6 case a wetlands. The seawater is allowed to flow freely into the area and then under the prevailing hydro geological conditions it is trapped into the lake. With the influence of the local microclimate, which is highly conducive to evaporation, the trapped quantity of seawater constantly condenses until salt is finally produced without any human intervention. The crystallization of salt usually starts in June and finishes by the end of July every year. In early August the lake usually "dries up" of brine and the whole phenomenon repeats itself the following winter. During the dry period people can walk in the lake and collect the produced salt. In fact, throughout this natural process, a chain of organisms similar to the one described above develops, constituting the biological system of the lake.

HELLENIC SALTWORKS S.A. was planning to construct a new Solar Saltworks in 'Aliki' Lake with a preliminary design shown in fig. 7 . The new investment was planning to cover the country's needs in salt and will offer jobs to local people taking into account that the unemployment in the Island is high. As it has already shown the construction of a Solar Saltwork in the area of "Aliki" lake will increase significantly both the number and the population of the encountered bird species in the lake and also the duration of their stay, finally resulted to an upgraded and more stable ecosystem! According to our study the new investment was going to upgrade the lakes' ecosystem and attract ecotourism to the Island.

We can also argue from the case of Kalloni Saltworks located in the nearby Island of Lesvos where just a few years after its process optimization and production area redesign:

- There was a remarkable increase in bird species and population

- Ornithologists reported movement of flamingos from 'Aliki' lake to Kalloni Saltworks

- Flamingos built nests in Kalloni Saltworks for three consecutive years, trying to reproduce for the first time in Greece

- A very strong ecotourism wave developed in the area, especially in months of April and May.

We just report here that the environmental study financed by the Greek State and undertaken by ENVECO S.A., 2001 unfortunately rejected the investment for environmental reasons! It claims that if a new Solar Saltworks will be constructed in the area of 'Aliki' lake three kinds of birds, namely Avocet, Himantopus himantopus and Varvara Duck will disappear!! 


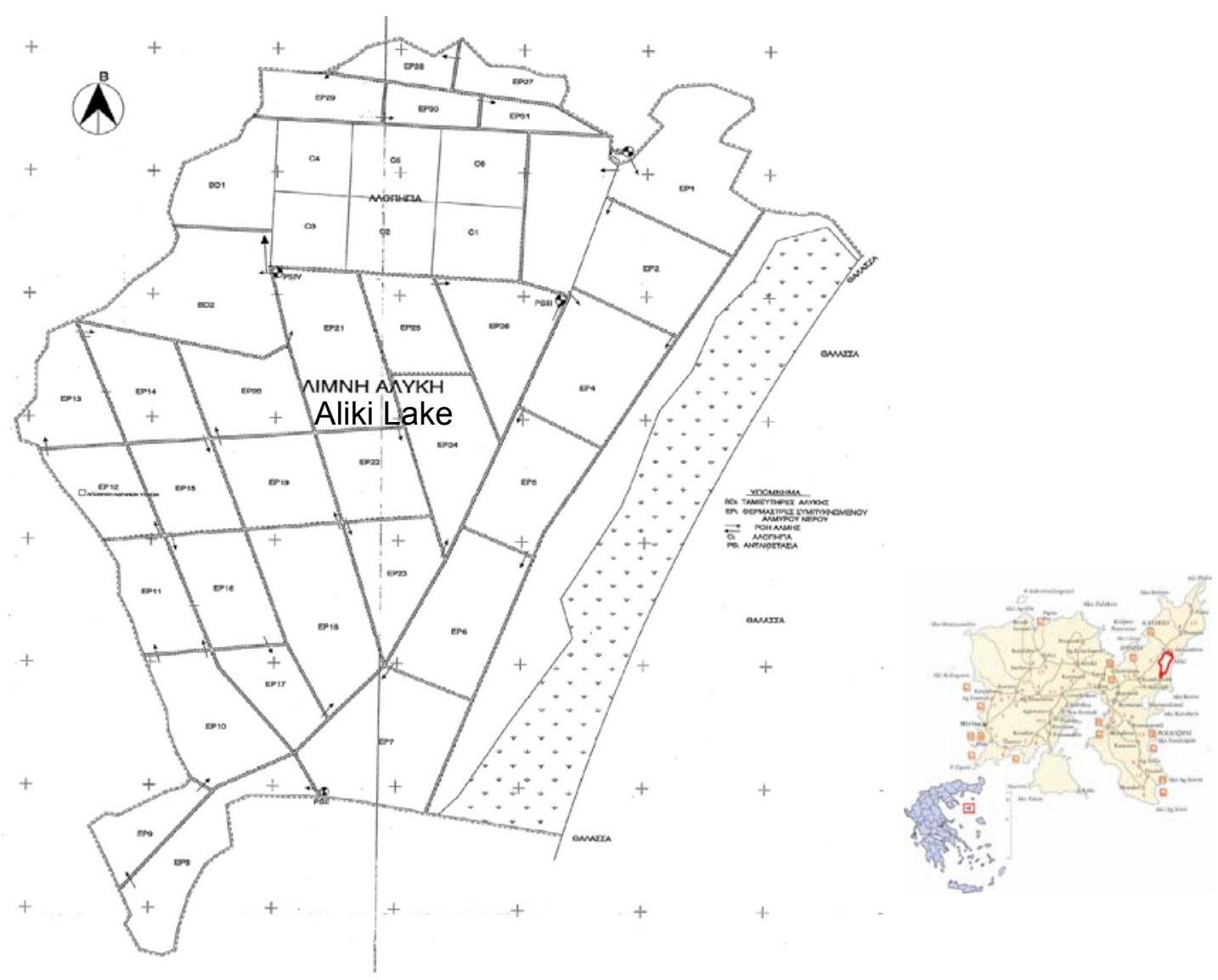

Figure 7. Design of Solar Saltworks in "Aliki" lake, Lemnos Island, Greece.
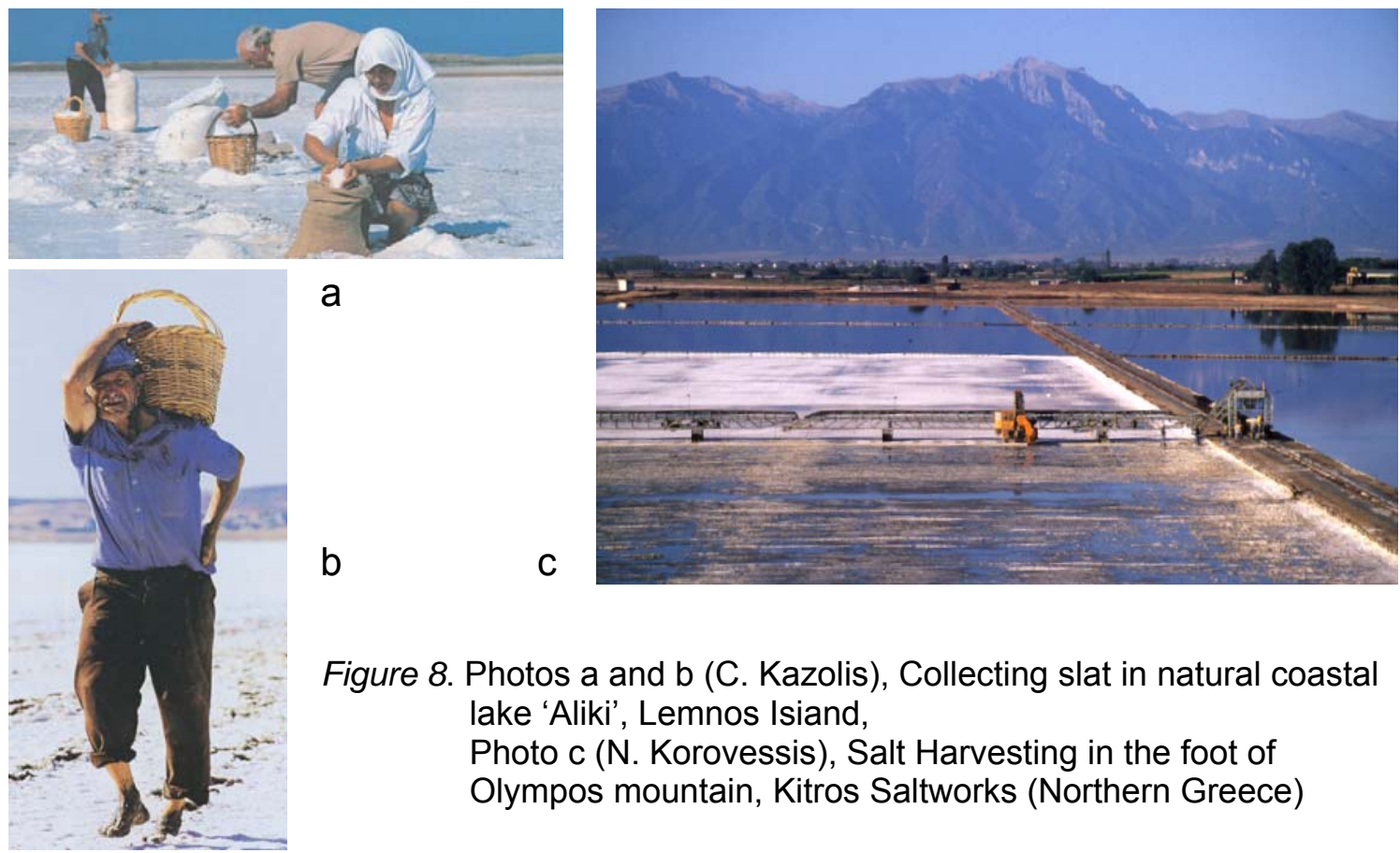

Figure 8. Photos a and b (C. Kazolis), Collecting slat in natural coastal lake 'Aliki', Lemnos Isiand,

Photo $\mathrm{c}$ (N. Korovessis), Salt Harvesting in the foot of Olympos mountain, Kitros Saltworks (Northern Greece) 


\section{REFERENCES}

Baas-Becking L.G.M. (1931) Historical Notes on Salt and Salt-Manufacture. Scientific Monthly, pp 434-446.

Bassegio G. (1974) The composition of seawater and its concentrates. Proc. $4^{\text {th }}$ int. Symp. Salt Vol. 2, pp. 351-358. Northern Ohio Geological Society, Inc., Cleveland, Ohio.

Davis J.S. (1974) Importance of microorganisms in solar salt production. Proc. $4^{\text {th }}$ int. Symp. Salt Vol. 2, pp. 369-372. Northern Ohio Geological Society, Inc., Cleveland, Ohio.

Davis J.S. (1980) Biological management of solar saltworks. Proc. $5^{\text {th }}$ int. Symp. Salt Vol. 1, pp. 265-268. Northern Ohio Geological Society, Inc., Cleveland, Ohio.

Davis J.S. (1993) Biological management for problem solving and biological concepts for a new generation solar saltworks. Proc. $7^{\text {th }}$ int. Symp. Salt Vol. 1, pp. 611-616. Elsevier Science Publishers B.V., Amsterdam.

ENVECO S.A. (2001) Environmental Study of the "Aliki" Lake Wetland, Lemnos Island. Specific Environmental Study. October 2001, Athens.

Korovessis N.A. and Lekkas T.D. (2000) Solar Saltworks Production Process Evolution - Wetland Function." Post conference Symposium Proceedings in $6^{\text {th }}$ Conference on Environmental Science and Technology. Pythagorion, Samos, $1^{\text {st }}$ September 1999, GlobalNEST, Athens. pp 11-30

McArthur J.N. (1980) An approach to process and quality control relevant to solar salt field operations in northwest of western Australia. Proc. $5^{\text {th }}$ int. Symp. Salt Vol. 1. Northern Ohio Geological Society, Inc., Cleveland, Ohio.

Young G. (1977) Salt, the Essence of Life. National Geographic, pp 381-401. 